\title{
Survey of dust formed in the TEXTOR tokamak: structure and fuel retention
}

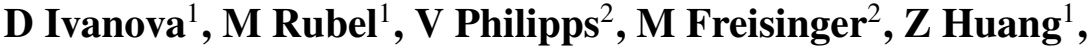 \\ H Penkalla ${ }^{2}$, B Schweer ${ }^{2}$, G Sergienko $^{2}$, P Sundelin $^{1}$ and E Wessel ${ }^{2}$ \\ ${ }^{1}$ Alfvén Laboratory, Royal Institute of Technology, Association EURATOM-VR, Teknikringen 31, \\ 10044 Stockholm, Sweden \\ ${ }^{2}$ Institute for Energy Research, Forschungszentrum Jülich, Association EURATOM-FZJ, 52425 Jülich, \\ Germany \\ E-mail: darya.ivanova@ee.kth.se
}

Received 13 October 2009

Accepted for publication 19 October 2009

Published 30 December 2009

Online at stacks.iop.org/PhysScr/T138/014025

\begin{abstract}
A detailed survey of erosion and deposition on plasma-facing components was performed in the TEXTOR tokamak. Co-deposits and dust particles were collected from graphite limiters and from several locations on the Inconel liner. The total amount of dust (loose material), originating mainly from carbon-rich co-deposits detached from the limiters and the liner, was around $2 \mathrm{~g}$, with sizes from $0.1 \mu \mathrm{m}$ to $1 \mathrm{~mm}$. The morphology and fuel retention was determined using microscopy methods, ion beam analysis and thermal desorption spectrometry. The study revealed differences in structure and fuel content between deposits from the toroidal and main poloidal limiters. There were also splashes, up to $1 \mathrm{~mm}$ in diameter, of molten metal (mainly nickel) on the toroidal limiters. Issues of the dust conversion factor (erosion-to-dust) are addressed and a comparison with results of previous dust surveys at TEXTOR is also briefly presented.
\end{abstract}

PACS number: 52.40.Hf

(Some figures in this article are in colour only in the electronic version.)

\section{Introduction}

In the fusion context the term 'dust' denotes all erosion products resulting from plasma-wall interaction processes and covers a range of particle dimensions from a few nanometers to millimeters. Dust formation in carbon-wall machines is mainly related to sputtering and chemical erosion of carbon by fuel species followed by long-range migration and re-deposition of hydrogenated carbonaceous species $\left(\mathrm{C}_{x} \mathrm{H}_{y} \mathrm{D}_{z}\right)$ in the form of co-deposited layers on plasma-facing components (PFC) [1-3] and is in remote areas with no direct line-of-sight to the plasma [4]. Such layers often flake and peel-off from the substrate, thus forming dust agglomerates $[1-3,5,6]$. There is no critical layer thickness when such a process starts. Dust release also occurs due to arcing; the effect has frequently been observed during the start-up phase [2]. Another mechanism of carbon dust production may be related to brittle destruction of carbon under localized high power loads [6, 7]. Melting, melt layer motion and eventually splashing of droplets would be the main mechanism for the formation of metal dust $[6,8,9]$.
The formation and accumulation of dust may have a serious impact on the economy and safety in operation of a reactor-class device [3,10-13]. The primary concern is related to consequences of oxygen and/or water contact with hot dust in the case of air and/or water leak during the plasma operation giving a high risk of pressure rise and explosion. A water leak would lead to the gasification of carbon by the water-gas shift reaction $\left(\mathrm{H}_{2}\right.$ and $\mathrm{CO}$ as products) and, in the case of metal dust, hydrogen release, e.g. $\mathrm{Be}+\mathrm{H}_{2} \mathrm{O} \rightarrow \mathrm{BeO}+\mathrm{H}_{2}$. A risk of mobilization and release of radioactively contaminated (neutron-activated and tritiated) products by explosion is also taken into account in safety assessments. Another category is the operational risk connected with degraded performance of diagnostic (e.g. first mirrors) or pumping components such as cryopanels. The impact of levitation of charged tritiated dust on plasma performance has also been addressed [14]. As a consequence, there are administrative and safety limits for dust content in the ITER vessel [10-12]. Access to the reactor in-vessel components will be extremely limited. Therefore, in the 
current tokamak physics program one has to determine, as accurately as possible, the impact of dust on plasma operation, the amount of dust formed (loose material and co-deposits), its distribution in the machine, physical and chemical properties such as size distribution, structure and composition with particular emphasis on the fuel content. The importance of such studies was already recognized at TEXTOR in the mid nineties [1, 2, 5]. Since then several comprehensive dust surveys have been carried out on the occasion of major shut-downs which gave access to all in-vessel components. Studies have also been done in ASDEX-Upgrade [15], Tore Supra [16, 17], JT-60 [18] and in JET [4], where a large amount (approx. $100 \mathrm{~g}$ ) of loose carbon flakes have been retrieved from one octant of the machine.

Dust particles moving in the plasma have been reported on many occasions, e.g. [2, 16]. In present day machines, the release of dust into the plasma is not considered as a serious operational or safety issue. Disruptions have only been noted in the case of a large amount of material being instantly released to the plasma.

The aim of this paper is to provide an overview of a broad dust survey and morphology studies in connection with the opening of the TEXTOR vacuum vessel in 2008. Recent data are also briefly compared with results obtained during previous surveys.

\section{Experimental procedures: dust collection and analysis}

The collection of dust was performed during the first hours after the opening of TEXTOR. Images in figures 1(a)-(c) show in-vessel components of TEXTOR. The locations from where the material for further analysis was sampled are indicated. In figure 1(b) one notices, on some tiles, patches of flaking layers whereas in figure 1(c) vast areas of the liner are covered with blackish soot-like rough deposits. A dust collector with a cascade series of meshes and filtering paper connected to a vacuum pump was used. It was done in order to separate debris of different sizes $(0.2-0.5$ and $0.5-1 \mathrm{~mm})$ from fine dust which was collected on the filtering paper. The material (loose particles) was taken separately from the bottom and the low-field side of the Inconel ${ }^{\mathbb{R}}$ liner, from the main graphite limiters pump toroidal belt ALT-II, poloidal and inner bumper and from the bottom shield of the dynamic ergodic divertor (DED). Magnetic and non-magnetic fractions were separated prior to further study. Sampling of deposits from the liner and limiters was done using adhesive carbon stickers and ultra-fine copper nets for microscopy and by direct scraping with a plastic knife.

Samples were examined with high-resolution scanning and transmission electron microscopy (SEM and TEM) combined with energy dispersive x-ray spectroscopy (EDX), Rutherford backscattering spectroscopy (RBS) and nuclear reaction analysis (NRA) using a $1.4 \mathrm{MeV}{ }^{3} \mathrm{He}^{+}$beam. The total fuel content was determined by means of thermal desorption spectrometry (TDS). In the latter case, the temporal evolution of fuel-related species versus temperature was measured by monitoring masses $2\left(\mathrm{H}_{2}\right), 3(\mathrm{HD}), 4\left(\mathrm{D}_{2}\right)$, $18-20$, i.e. water group and various hydrocarbons $\mathrm{C}_{x} \mathrm{H}_{y} \mathrm{D}_{z}$. Calibration of the quadrupole mass analyzer was based on the consecutive injection of gases $\mathrm{H}_{2}, \mathrm{D}_{2}$ and $\mathrm{CH}_{4}$ into the
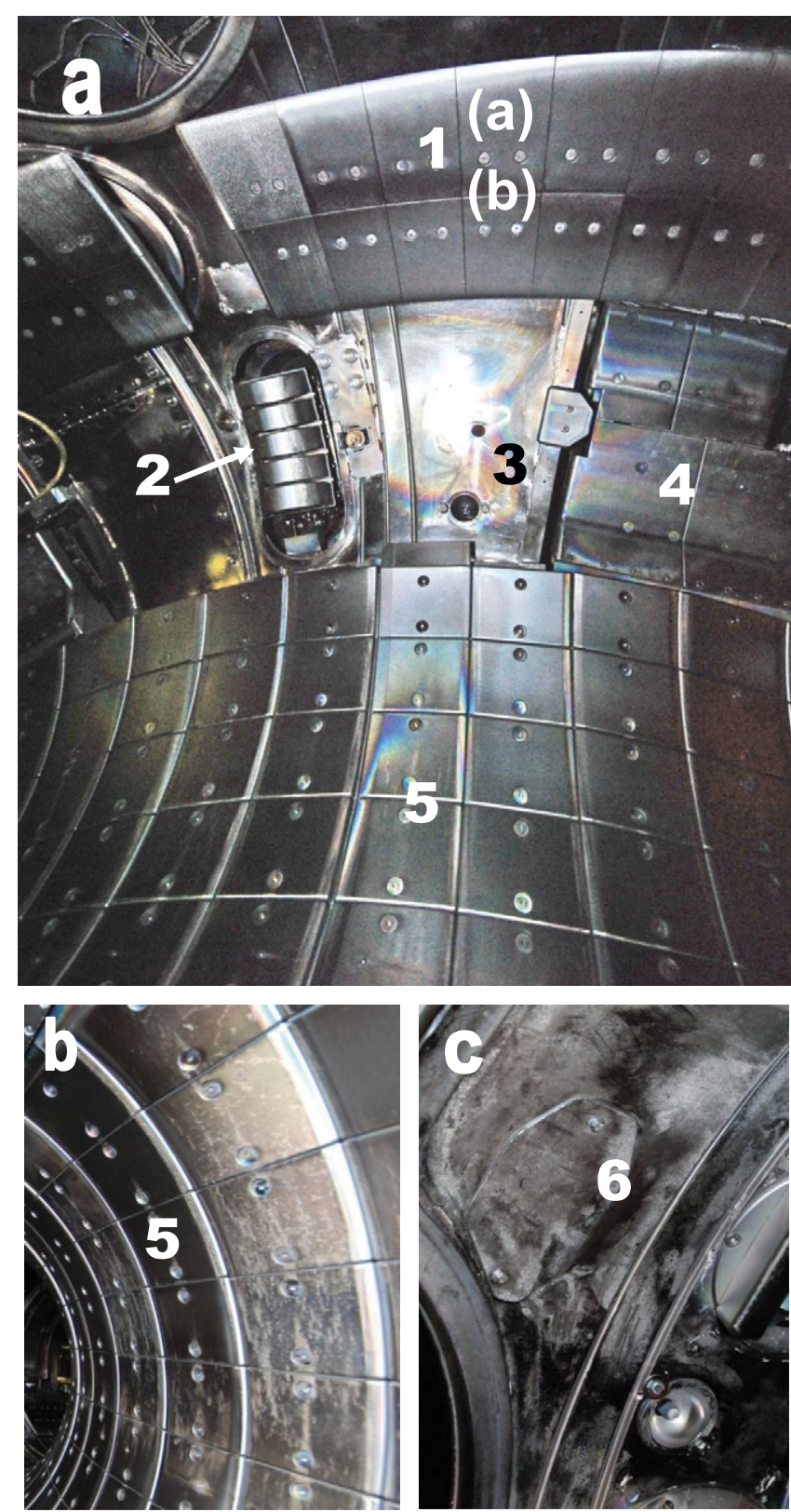

Figure 1. PFCs of TEXTOR. (a) Bottom part of the torus; (b) details of the inner wall and (c) the liner on the low field side. 1. ALT-II toroidal belt pump limiter: (a) erosion zone and

(b) deposition zone; 2 . main poloidal limiters; 3 . bottom of the Inconel liner; 4. bottom DED shield; 5. inner wall bumper limiter; 6 . blackish dust on the Inconel liner.

TDS chamber. A calibration factor for HD was approximated with an arithmetical mean of the calibration factors for $\mathrm{H}_{2}$ and $\mathrm{D}_{2}$. The desorption was done at temperatures of up to $1273 \mathrm{~K}$, the heating rate was $0.5 \mathrm{~K} \mathrm{~s}^{-1}$ on most occasions. The efficiency of fuel removal, by long-term outgassing at $623 \mathrm{~K}$, was also determined. The background desorption of the empty TDS chamber was performed for both the experiments. The sensitivity is at the level of $6 \times 10^{11}$ at s ${ }^{-1}$ at a temperature of $1273 \mathrm{~K}$.

\section{Results}

\subsection{Deposit structure and fuel content}

The SEM images in figure 2 show the topography of flakes isolated from the deposition zone of the ALT-II tile 

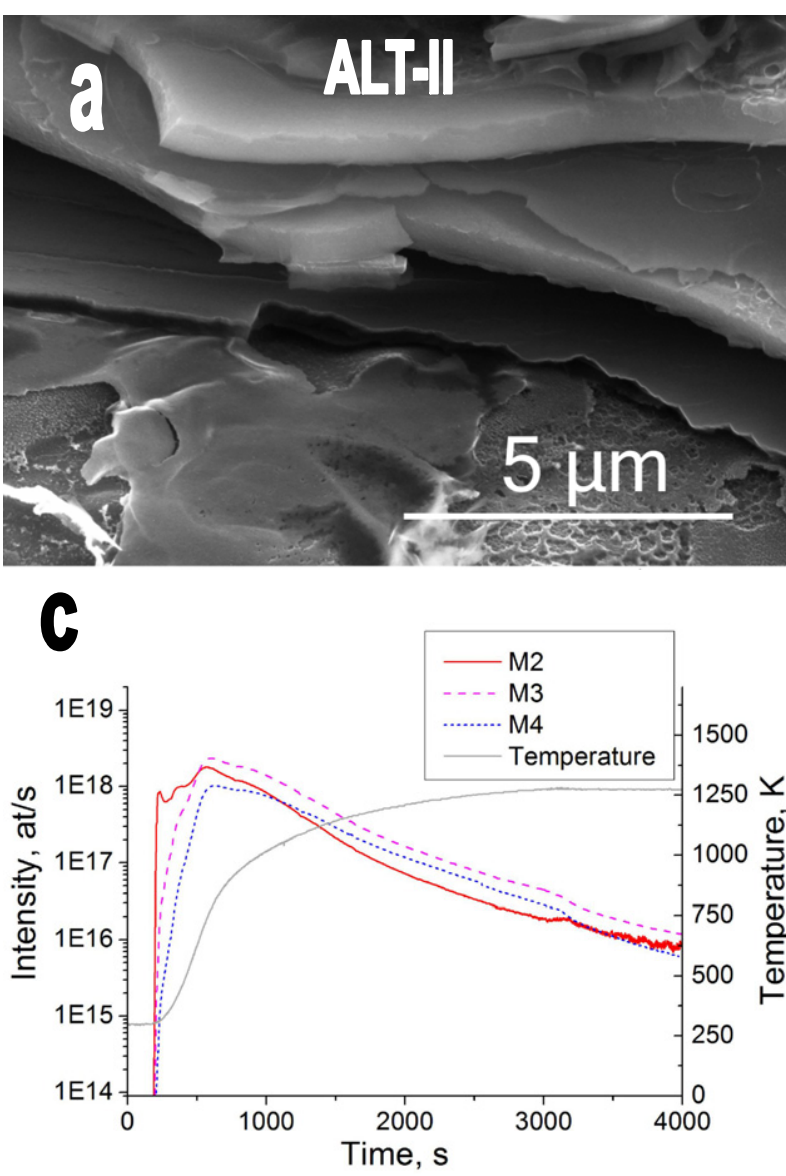

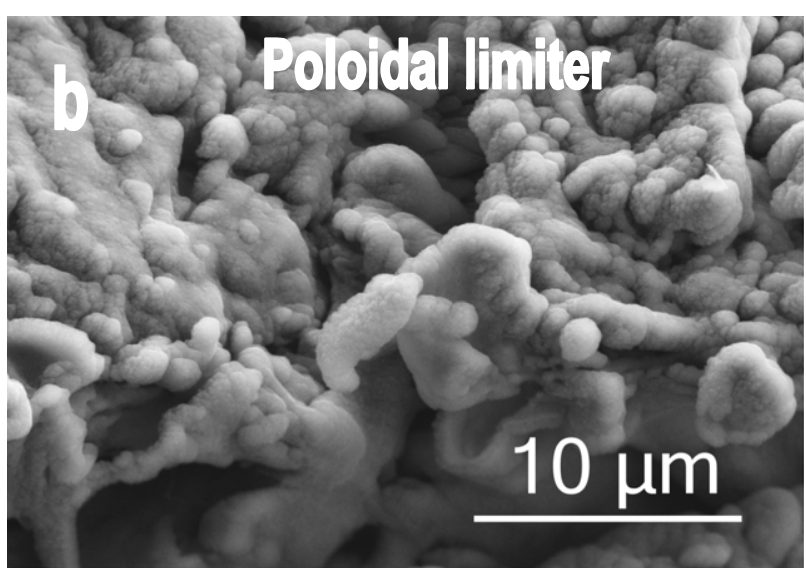

d

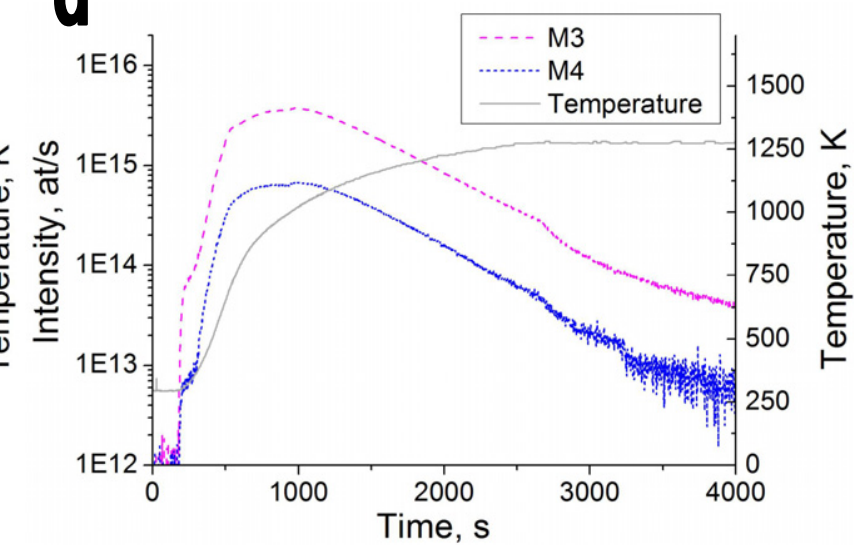

Figure 2. SEM images showing the topography of flaking co-deposits from the toroidal ALT-II (a) and poloidal (b) limiters and corresponding TDS characteristics for release of deuterium-containing species from the two types of limiters (c) and (d), respectively. Carbon-based co-deposits and dust from various locations: (a) granular structures from the main poloidal limiter, (b) layered deposit on the ALT-II (c) carbon debris from the bottom of the liner.

Table 1. Retention of $\mathrm{H}$ and $\mathrm{D}$ in dust and co-deposites from various locations. The atomic density of carbon is $4.5 \times 10^{22} \mathrm{~g}^{-1}$.

\begin{tabular}{lccc}
\hline $\begin{array}{l}\text { Location in } \\
\text { TEXTOR }\end{array}$ & $\begin{array}{c}\mathrm{H} \\
\left(10^{20} \mathrm{at} \mathrm{g}^{-1}\right)\end{array}$ & $\begin{array}{c}\mathrm{D} \\
\left(10^{20} \mathrm{at} \mathrm{g}^{-1}\right)\end{array}$ & $\mathrm{D} / \mathrm{C}$ \\
\hline ALT-II tile & 42.7 & 34.8 & 0.087 \\
& 43.8 & 31.1 & 0.079 \\
Poloidal limiter & - & 0.12 & 0.0003 \\
ICRF antenna grill & 8.3 & 6.6 & 0.015 \\
Floor (liner's bottom) & 1.28 & 0.2 & 0.001 \\
\hline
\end{tabular}

(figure 2(a)) and deposits from the main poloidal limiter (figure 2(b)). Thermal release of fuel from the two types of deposits is shown in figure 2(c) and (d), respectively. The results of TDS measurements for samples from several locations are summarized in table 1 which provides data for the total amount of desorbed hydrogen isotopes $(M=3$ and 4) and deuterium-to-carbon (D/C) ratio. Masses 19 and 20 are not shown because their intensity was two orders of magnitude smaller than the intensity of the $\mathrm{HD}$ and $\mathrm{D}_{2}$ signals. Despite the rather small amount of each dust sample (milligrams) the background level for the studied masses did not exceed $1 \%$ of the total intensity. All data presented in the paper have been normalized for a specimen mass of $1 \mathrm{~g}$.

The largest amount of deuterium and $\mathrm{D} / \mathrm{C}$ ratio $(\sim 0.08)$ is found in stratified layers from the deposition zone on ALT. The layers also contain hydrogen $(\mathrm{D} / \mathrm{H}$ in the range
0.7-0.8) whose origin is most probably attributed to the adsorption of water vapor from the ambient atmosphere when the flakes are stored after retrieval from the vacuum vessel of TEXTOR. The rough granular deposit on the poloidal limiter contains a minute amount of deuterium $(\mathrm{D} / \mathrm{C}=0.0003)$. It is related to the high surface temperature of limiters during plasma operation. The hydrogen content in this case could not be quantified exactly because the pressure rise caused by the release of hydrogen species $\left(\mathrm{H}_{2}\right.$ and $\left.\mathrm{H}_{2} \mathrm{O}\right)$ at the very beginning of desorption was greater than the operational range of the quadrupole mass analyzer. This observation supports the statement that the hydrogen presence is associated with water adsorption in the porosity of deposits. It may occur efficiently in deposits of high roughness and large amount of open pores. Unfortunately, proper porosity measurements could not be performed in this case because of too small a quantity of material (mg range) available for study.

The fuel content in deposits on the ion cyclotron resonance heating (ICRH) antenna grill and loose dust from the liner's bottom is significantly smaller than on ALT-II. The reason for a reduced fuel retention in flakes from the antenna grill has been discussed previously [19]: effective release of carbon and deuterium by energetic particles generated by ICRH pulses. The small fuel content in loose dust hoovered from the bottom of the liner should be interpreted with care. The material collected (less then $2 \mathrm{~g}$ in total) 
Table 2. Efficiency of deuterium release by long-term outgassing of co-deposits on ALT-II.

\begin{tabular}{lccc}
\hline Heating & $\mathrm{H}_{2}(\%)$ & $\mathrm{HD}(\%)$ & $\mathrm{D}_{2}(\%)$ \\
\hline 623 K for 3 days & 34.1 & 11.9 & 5.2 \\
1273 K (final stage) & 65.9 & 88.1 & 94.8 \\
\hline
\end{tabular}

was composed of species with highly diversified size and composition: from nano-size carbon dust to larger debris (0.1-1 mm) of graphite, ceramics and metal; see section 3.2. As a consequence, the TDS result $(\mathrm{D} / \mathrm{C}=0.001)$ may not exactly reflect carbon-related fuel content.

The survey has confirmed that fuel retention in TEXTOR is highly localized: the majority of deuterium is accumulated in deposition zones on ALT-II [20, 21]. Therefore, flaking layers from that area have been selected for long-term outgassing at a constant temperature of $623 \mathrm{~K}$. The aim was to assess the efficacy of fuel removal at the maximum bake-out temperature of the ITER divertor. The desorption was done in two stages: long-term annealing at $623 \mathrm{~K}$ for $70 \mathrm{~h}$ followed by a steady temperature rise $\left(\sim 0.1 \mathrm{~K} \mathrm{~s}^{-1}\right)$ to $1273 \mathrm{~K}$ in order to complete the desorption. The results presented in table 2 show that only about $10 \%$ of deuterium was removed by long-term treatment at $623 \mathrm{~K}$. The efficient removal of the remaining $90 \%$ could only be achieved at greater temperatures. It clearly indicates a limited use of outgassing at moderate temperatures as a method for fuel removal from carbon-based co-deposits in ITER.

\subsection{Dust from the liner and limiters}

All SEM and TEM studies were accompanied by EDX in order to identify the elemental composition arising from material mixing. Particular interest was focused on the identification of objects consisting essentially of pure carbon or only metal species.

Figure 3(a) shows debris collected from the bottom of the liner, whereas the TEM image (figure 3(b)) presents an amorphous deposit with embedded nano-size particles of crystalline matter, as confirmed by electron diffraction (see the pattern in figure 3(c)). In all cases the elemental composition determined by EDX revealed that the crystalline material was composed of carbon. The origin of the larger debris $(0.2-0.8 \mathrm{~mm})$ in figure 3 may be attributed to the damage of the graphite tile during the installation. However, the presence of fine crystalline carbon matter points to another possible mechanism of material disintegration and production of such objects: brittle destruction. One may tentatively suggest that small crystalline graphite objects in the loose material could be associated with brittle destruction of carbon PFC caused by highly localized power loads due to disruptions. The final confirmation of that phenomena taking place in TEXTOR is still needed by systematic combined studies using cameras and spectroscopy methods for dust tracing in the plasma and by detailed dust survey during the next opening of the TEXTOR vacuum vessel. It should be stressed that until now no direct evidence of brittle destruction has been found in present day tokamaks, but it was detected in a reversed field pinch as a result of highly localized wall-locked modes [2]. Therefore, the effect cannot be excluded for future devices
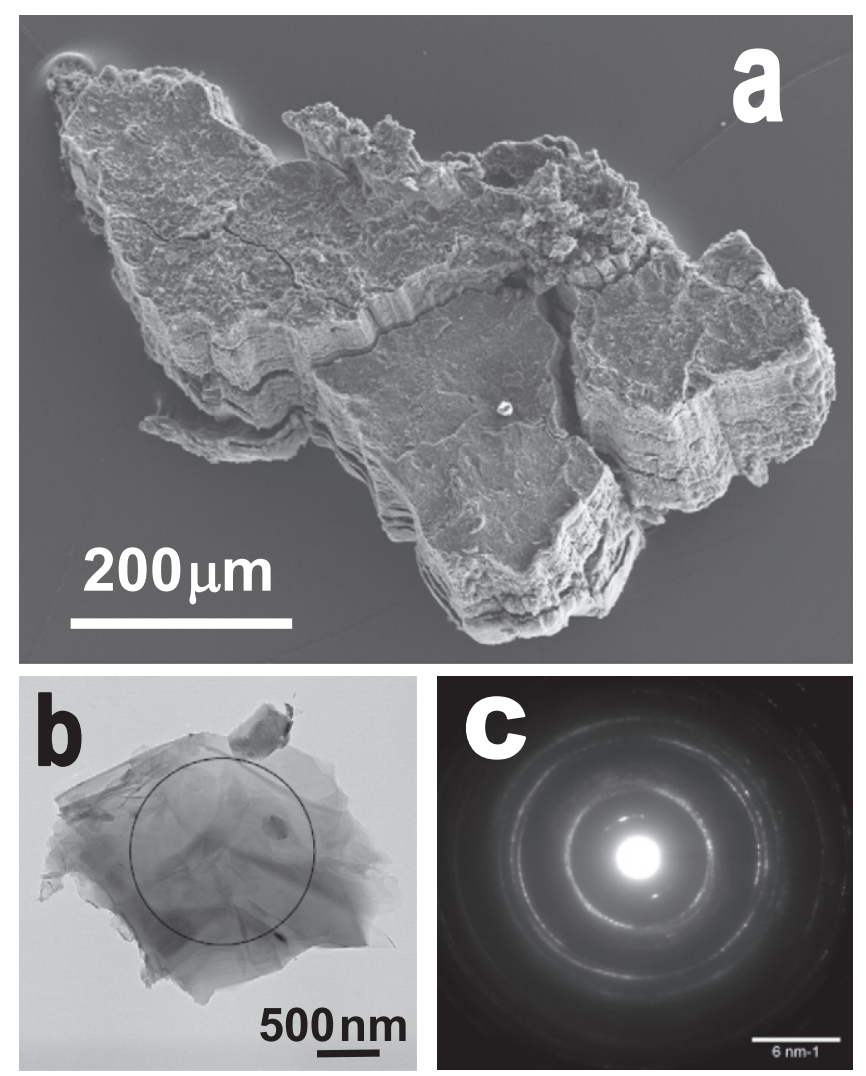

Figure 3. (a) SEM images of graphite debris collected from the bottom of the liner (a); dust from the inner bumper limiter: amorphous carbon co-deposit with embedded nano-size particles of crystalline carbon (b) and corresponding diffraction pattern (c).

in the case of giant edge localized modes (ELM), vertical displacement events (VDE) or disruptions.

Figure 4 shows metal species retrieved from the bottom of the liner (figure 4(a)) and a splash from the surface of ALT-II (figures 4(b) and (c)). The objects are composed predominantly of nickel, chromium and iron thus suggesting that these are erosion products from the liner or ICRF antenna grill. Careful analysis of the splash shape indicates that the original molten metal droplet did not re-solidify instantly after hitting the graphite substrate. It was still rotating when solidifying, as inferred from the twisted layers (left side in figure 4(b) marked with X). This 'layered' structure is also visible in figure 4(c) which additionally allows for determination of the grain size: $5-15 \mu \mathrm{m}$. At the tips of the protruding grains one finds carbon co-deposits, as proven by secondary electron images (atomic number contrast) and EDX. Further analysis of splashes and ion tracks present on the surface is under way in order to determine the droplet velocity with respect to the magnetic field direction.

\section{Discussion}

Dust is not a safety or operational problem in present-day devices. Therefore, studies are carried out from the ITER perspective. The most intriguing and important issue is the so-called conversion factor, i.e. the ratio of the total amount of eroded and transported material to the amount of loose matter found in the vacuum vessel: 'erosion-to-dust'. First of all, the determination of the total erosion meets difficulties because 

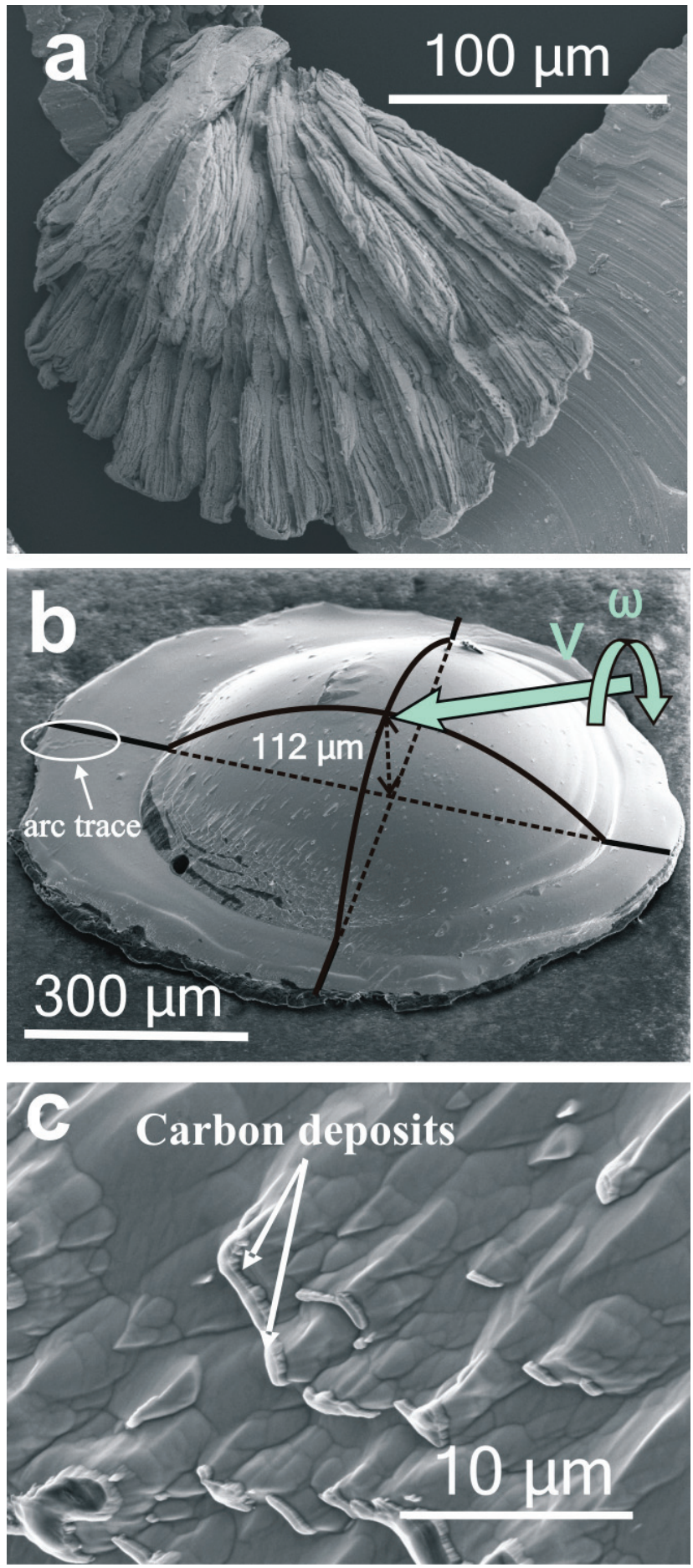

Figure 4. Metal (Ni-Cr-Fe) objects: (a) dust from the liner and (b) a splash with (c) carbon deposits on edges.

part of the eroded material, especially in the case of carbon, is pumped out. The second difficulty arises from the fact that loose dust contains a variety of species including ceramics from broken diagnostics, wall heating elements, tiny pieces of mechanically damaged tiles during the PFC installation, etc. As a consequence, the meaning of the conversion factor is narrowed to: 'the amount of eroded and re-deposited matter to the amount of loose dust of operational origin'. The latter is somewhat difficult to define. In the following, the consideration of dust will be limited to carbon-based co-deposits referred to as the total erosion and the amount of loose carbon species.

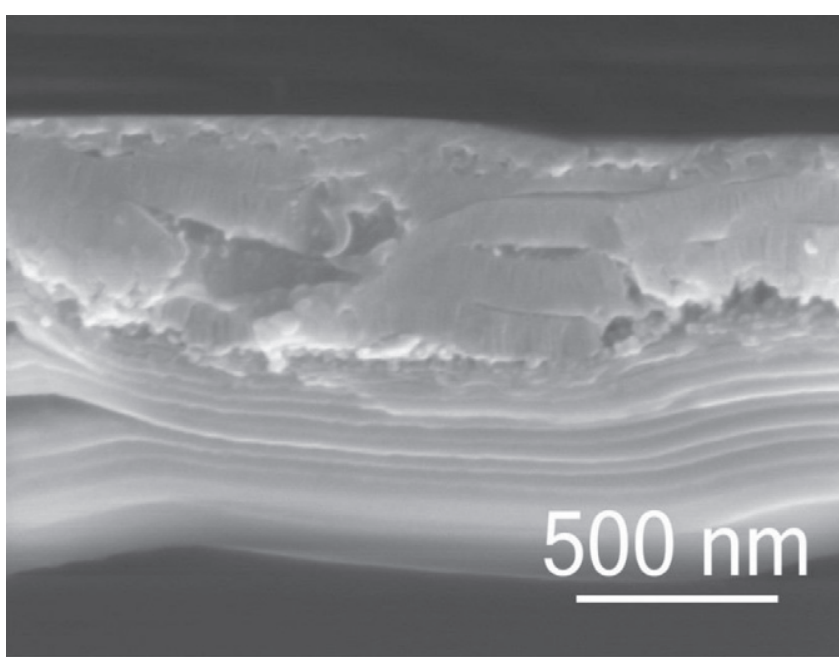

Figure 5. Stratified dust collected from the Inconel liner: splitting of flakes into $30 \mathrm{~nm}$ strata after one year in air.

The total amount collected by vacuum cleaning of limiters and the liner (bottom and low-field side) was about $2.0 \mathrm{~g}$. The dominant part of this material is constituted of larger (up $1 \mathrm{~mm}$ ) debris which could be related to the in-vessel work, i.e. installation of tiles. More exact numbers cannot be given because the ultra-fine dust could not be weighed: (a) it sticks to the filtering paper; (b) some fine matter could not be removed from PFC because of strong adhesion to the substrate, probably due to Van der Waals forces as suggested in [22]. After subtracting the mass of above-mentioned larger debris and ceramics the amount of carbon matter is $0.1-0.2 \mathrm{~g}$. The other side of the equation for the conversion factor includes the amount of material eroded and re-deposited on PFC. Results of recent studies are consistent with previous findings that co-deposits in TEXTOR are predominantly formed in the deposition zones of the ALT-II tiles [5, 20]. The total amount of carbon in these $20-40 \mu \mathrm{m}$ layers of density around $1.4 \mathrm{~g} \mathrm{~cm}^{-3}$ is assessed at the level of approximately $40 \mathrm{~g}$. It leads to a conversion factor of 200-400.

The process that may significantly influence the conversion factor is the splitting, flaking and eventually peeling-off of the layer. The process is enhanced by exposure of the layers to air. The SEM image in figure 5 show layers on the liner after contact with air. These stratified co-deposits split into $20-30 \mathrm{~nm}$ thin strata that easily disintegrate into very fine matter. As already discussed in previous papers [22], accumulation of water vapor in porous dust pieces and deposits causes splitting and flaking of the layers. The effect is enhanced when the layer is again subjected to vacuum conditions either in the SEM chamber or in a tokamak after a shut down period. This issue is still to be examined in more detail because the same may be expected in a beryllium wall machine, because beryllium reacts easily with water and oxygen in air.

\section{Concluding remarks}

As already stated, the results of the systematic dust survey in TEXTOR confirm several previous datasets. The new important finding is evidence for the existence of carbon 
debris, $10 \mathrm{~nm}-200 \mu \mathrm{m}$, in the collected material. This may be a product of brittle destruction. In such a case it would be the first documented example in a tokamak. To clarify this point, more studies are needed during the TEXTOR operation (spectroscopy and cameras) and at the next inspection of the vessel. From the ITER perspective the issue of brittle destruction and dust formation in present-day machines deserves and requires a comprehensive approach. It is expected that a very detailed survey of dust in JET before the installation of the ITER-Like Wall (ILW) [23] will shed light on the real extent of carbon and beryllium dust production that a reactor-class device may face. The issue of tungsten and beryllium metal dust will be one of the important subjects for the operation of JET with ILW.

\section{Acknowledgments}

This work was funded jointly by the Swedish Research Council, Forschungszentrum Jülich and by the European Communities under the Contracts of Association between EURATOM and VR and FZJ. The views and opinions expressed herein do not necessarily reflect those of the European Commission. This work was carried out within the framework of EFDA.

Published under licence from EURATOM.

\section{References}

[1] Winter J 1998 Plasma Phys. Control. Fusion 40 1201-10

[2] Rubel M et al 2001 Nucl. Fusion 411087

[3] Federici G et al 2001 Nucl. Fusion 411967

[4] Coad J P et al 2001 J. Nucl. Mater. 290-293 224

[5] Rubel M et al 2003 Phys. Scr. T 103 20-4

[6] Linke J et al 2000 Phys. Scr. T 91 36-42

[7] Bolt H et al 1999 Phys. Scr. T 8194

[8] Hassanein A et al 1997 J. Nucl. Mater. 241-243 288

[9] Sergienko G et al 2007 J. Nucl. Mater. 363-365 96

[10] Roth J et al 2009 J. Nucl. Mater. 390-391 1-9

[11] Grisolia C et al 2007 Fusion Eng. Des. 822390

[12] Rosanvallon S et al 2008 Fusion Eng. Des. 831701

[13] Rosanvallon S et al 2009 J. Nucl. Mater. 390-391 $57-60$

[14] Winter J, Fortov V E and Nefedov A P 2001 J. Nucl. Mater. 290-293 509

[15] Rohde V et al 2009 Dust Investigations at ASDEX Upgrade PFMC-12 Jülich, Germany, C5

[16] Chappuis P et al 2001 J. Nucl. Mater. 290-293 245

[17] Pégourié B 2009 J. Nucl. Mater. 390-391 550-5

[18] Gotoh Y et al 2006 J. Nucl. Mater. 357138

[19] Fortuna E et al 2007 J. Nucl. Mater. 367-370 1507

[20] Rubel M, Wienhold P and Hildebrandt D 2001 J. Nucl. Mater. 290-293 473

[21] Wienhold P et al 2003 J. Nucl. Mater. 313-316 311

[22] Grisolia C et al 2009 J. Nucl. Mater. 386-388 871-3

[23] Matthews G et al 2007 Phys. Scr. T 128137 